\title{
Carbon Capture and Storage (CCS) Deployment - Can Canada Capitalize on Experience?
}

\author{
Drew Thomson, CMA FCMA (I), Anshuman Khare, Ph.D (2)
}

\begin{abstract}
This paper presents an overview of Canada's experience with carbon Capture \& Storage (CCS) initiatives. While discussing various options available, the paper examines the success Canada has had with carbon capture and storage and why it is advantageous for Canada to make it part of their environmental sustainability effort. The paper also discusses the barriers and challenges in carbon capture and storage deployment. The paper ends with some speculation about how the technology can be adopted quickly if some organizations were more proactively involved with it.

Carbon capture and storage has a potential to change how we reduce our greenhouse gas (GHG) emissions in the future. However, it has a long way to go as organizations start adopting it and unanswered questions get answered in the process. It certainly is a technology worth looking at as it can affect our future climate change initiatives.
\end{abstract}

Keywords: Climate change, carbon capture and storage (CCS), CO2 emissions, environmental sustainability, Canada.

(I) The Law Society of Alberta

(2) Centre for Innovative Management - Athabasca University, 30I-22 Sir Winston Churchill Avenue, St. Albert AB T8N IB4, CANADA.

E-mail: anshuman@athabascau.ca; Fax: 780-4592093. 


\section{Introduction}

Canada is a nation rich in natural resources. The nation's economic wealth has been built on a long history of extraction, processing, export and consumption of this naturally endowed bounty. In this century, Canada (and in particular provinces like Alberta, Saskatchewan, Newfoundland and Nova Scotia) is benefiting from a world economy driven by fossil fuels. However, there is a cloud over this good fortune. The current and predicted rates of fossil fuel consumption are a serious environmental concern. Greenhouse gas (GHG) emissions, primarily from the burning of coal and oil, are now at levels that are contributing to global climate change."Unless there is a change, the world will see much higher levels in the future - levels that are predicted to lead to damaging climate change" (Socolow \& Greenblatt, 2004, p. 8).

Given the need to limit GHGs, the international community is looking for new ways to manage this situation. Technologies to take advantage of alternative energy sources (solar, wind, biomass, tidal etc.) are rapidly being developed. Conservation methods are also being introduced in an attempt to increase efficiencies in the way humans consume fossil fuels. That said, the world's reliance on fossil fuels will not abate in the foreseeable decades. "Most scenarios project that the supply of primary energy will continue to be dominated by fossil fuels until at least the middle of the century" (IPCC, 2005. p. 3). It is unlikely that conservation methods will fully address the planet's inability to absorb the levels of GHGs humans currently demand to maintain modern economic activity. To help strike this balance between economic development and environmental sustainability, a solution may lie deep below the earth's surface. Carbon capture and storage (CCS) may hold the key to striking this balance.

\section{How CCS works}

When fossil fuels such as coal, natural gas or oil are burned or processed to produce energy or other petroleum based products, carbon dioxide (CO2) and other pollutants are generated as byproducts. Presently, these emissions are released into the atmosphere in the form of GHGs. CCS is a process through which $\mathrm{CO} 2$ can be diverted from the atmosphere by capture and storage. "CCS is a waste management strategy for carbon dioxide. It does not reduce the production of $\mathrm{CO} 2$, but it provides a depository to keep it from harming the environment" (Griffiths, Cobb \& Marr-Laing, 2005, p. vii).

The CCS process has three distinct elements. First, the emitted CO2 must be captured and compressed to stop it from immediately dissipating into the atmosphere. Next, the compressed $\mathrm{CO} 2$ is transported to a suitable storage site. Finally, the $\mathrm{CO} 2$ is injected into the storage site. Potential sites for long-term storage of $\mathrm{CO} 2$ are either geological (depleted oil and gas reservoirs, deep saline aquifers or coal seems), on the ocean floor (ocean storage concept), or through an industrial process that permanently fixates the $\mathrm{CO} 2$ into inorganic carbonates using chemical reactions or industrial use of $\mathrm{CO} 2$ for production of carbon compounds or chemicals (IPCC, 2005).

\section{I Capture and compression}

It is practical to capture $\mathrm{CO} 2$ emissions from large stationery (or point) sources. Worldwide, the bulk of $\mathrm{CO} 2$ emissions from such large point sources are coal or natural gas fired power plants. "Since power generation is responsible for over $29 \%$ of global CO2 emissions, capturing from electricity generation plants offers the best initial potential for capturing $\mathrm{CO} 2$ generated from fossil fuel use" (IEA/OECD, 2004, p. I5). Secondary fixed point sources of $\mathrm{CO} 2$ are industrial facilities such as refineries, cement plants, oil and gas processing plants, steel plants and petrochemical processing facilities (IPCC, 2005). Given the scale required to capture enough $\mathrm{CO} 2$ to mitigate the negative effects of GHGs and climate change, it is probably not economically feasible to capture these emissions from more distributed sources such as transportation, agriculture, housing or buildings (Griffiths et al., 2005).

The most promising $\mathrm{CO} 2$ capture technologies are post-combustion and pre-combustion processes. In the more conventional post-combustion approach, $\mathrm{CO} 2$ is captured from the gases emitted from burning coal or natural gas to produce energy. The pre-combustion method is used when hydrogen and CO2 are stripped from natural gas. Hydrogen is used either to produce electricity (with only water as a byproduct) or in other industrial processes such as bitumen refining. The $\mathrm{CO} 2$ that is currently emitted into the atmosphere through both the pre and post combustion processes could be captured and made ready (compressed) for transportation to a suitable storage site. A third capture technique is oxyfuel combustion. Similar to post-combustion, the fuel is burned in pure oxygen which results in a much purer $\mathrm{CO} 2$ stream than when the fuel is burned in air. This is a relatively more elaborate process than regular post-combustion $\mathrm{CO} 2$ capture and is, consequently, in the demonstration phase of development (Williams, 2006).

\subsection{Transportation}

Once the $\mathrm{CO} 2$ is captured and compressed, it can be transported to storage sites either through pipelines or mobile transport facilities (trains, ships or trucks). Again, given the amount of $\mathrm{CO} 2$ that would be required to transport for storage, using pipeline facilities is the most feasible transportation option. In terms of rail or road transport, "Trains and trucks 
are thought to be too small-scale for projects of this size" (Williams, 2006, p. 4). Shipping of CO2 would be similar to shipping liquefied natural gas. Consequently, this would likely be economically feasible under particular circumstances (IPCC, 2005).

\subsection{Storage}

The final stage in the CCS process is long term storage of $\mathrm{CO} 2$. To achieve successful storage in terms of mitigating the damaging environmental effects of GHG accumulations in the atmosphere, such storage must be relatively permanent. Permanence means that the $\mathrm{CO} 2$ must not leak back into the atmosphere at any significant rate for hundreds of years. As pointed out by Williams "The IPCC concluded that aggregate leakage rates of $\mathrm{I}-10 \%$ over 100 years or $5-40 \%$ over 500 years would maintain storage as a viable option for reducing emissions" (2006, p. 6).

To achieve this kind of permanence of storage, injection of $\mathrm{CO} 2$ must take place at depths in excess of 800 metres so that geological cap rock and other geochemical trapping mechanisms can prevent the gas from migrating back to the surface (IPCC, 2005). These kind of geological formations are found both on and offshore in various locations around the world. Deep saline aquifers and depleted oil and gas reservoirs are generally considered the most suitable geological formations for long-term $\mathrm{CO} 2$ storage.

A possible storage location for $\mathrm{CO} 2$ is at the bottom of deep sea beds. $\mathrm{CO} 2$ can either be injected into the water column for dissolution or injected through pipelines to the deep sea bed. The $\mathrm{CO} 2$ would then remain at the bottom of the sea bed in the form of a "lake" since liquid CO2 is denser than sea water. Storage of $\mathrm{CO} 2$ in this manner is considered highly controversial since "little is known about the impact of increasing $\mathrm{CO} 2$ concentrations would have on the oceanic ecosystems" (IEA/OECD, 2004, p. 93). As pointed out by Holliday, Schmidheiny \&Watts "Some researchers and environmental organizations have also expressed concerns that storing $\mathrm{CO} 2$ in the deep oceans could have detrimental effect on marine life and that sudden releases of stored carbon could harm humans" (2002, p. 227). While current models suggest that CO2 injected in oceans can be isolated from the atmosphere for hundreds of years, concerns over the effects on ocean ecology due to increased acidity caused by increased levels of $\mathrm{CO} 2$ render this option highly unlikely in the foreseeable future (IPCC, 2005).

Finally, injection of $\mathrm{CO} 2$ into coal bed seams to recover methane is in the early stages of research and development. The advantage of this technology is that, because of the way $\mathrm{CO} 2$ reacts with coal, once it is injected in the coal bed it is sequestered permanently (Griffiths et al., 2005). Also, the dis- placed methane gas can be recovered and utilized as an energy source.

\section{The GHG reduction potential of CCS}

As will be discussed in subsequent sections of this paper, a major barrier to deployment of CCS is the cost of developing the appropriate technology and infrastructure in Canada and other parts of the world. Consequently, it is important to understand the known potential of CCS storage relative to the need to reduce GHGs in the next few decades.

\section{I Global potential}

The IPCC views CCS as "an option in the portfolio of mitigation actions for stabilization of atmospheric greenhouse gas concentrations" (2005, p. 3). In conjunction with the development of energy efficiency measures and continued conversion to renewable and nuclear energy sources, CCS "has the potential to reduce overall mitigation costs and increase flexibility in achieving greenhouse gas emission reductions" (IPCC, 2005, p. 3). In this context, CCS is not viewed as the sole solution to mitigating increases in GHGs beyond unsustainable levels. It is, however, viewed as part of a GHG mitigation program that can bridge the world's energy needs through the current century until other energy sources are able to meet human needs. IPCC scenario studies estimate that $20-40 \%$ of global fossil fuel $\mathrm{CO} 2$ emissions could be amenable to CCS by the middle of the century. This includes electrical generation (30-60\%) and industry (30-40\%) (IPCC, 2005).

\subsection{Canadian potential}

The Canadian government has announced its intention to reduce GHGs by $20 \%$ in 2020 from current levels and $60-70 \%$ by 2050. According to the ecoEnergy Carbon Capture and Storage Task Force (eCCSTF), the Canadian potential for $\mathrm{CO} 2$ capture and storage is "roughly 40 percent of Canada's projected GHG emissions in 2050" (2008, p. v). Relative to Canadian emission reduction targets over the next few decades, CCS has the potential to contribute significantly to curbing dangerous GHG emissions from fossil fuel energy production.

\section{Deployment of CCS}

\section{I Canadian deployment of CCS}

There are a number of factors that make Canada an attractive candidate for widespread deployment of CCS in the coming decades. As a major international producer of fossil fuels, much of the technology required for the deployment of CCS already exits in Canada. "The CCS component technologies (capture, 
transport, and storage) all exist today at industrial scale" (eCCSTF, 2008, p. vi).

The geological formations in the Western Canadian Sedimentary Basin (WCSB) are considered as ideal for CO2 storage. Based on research performed by the Alberta Geological Survey, the area of the WCSB most suitable for CO2 storage is located in the southwestern area of Alberta (Griffiths et al., 2005). "Liquid CO2 is lighter than water and therefore tends to travel upwards: thus, suitable geological formations must have 'cap' rock to act as a barrier to its movement" (Williams, 2006, p. 4). This type of cap rock is prevalent in the WCSB, particularly in Southwestern Alberta. According to the eCCSTF, the WCSB "deep rock formations are highly permeable, they are saturated with extremely saline and therefore unusable fluids, and they are not connected to ground water or other valuable minerals" $(2008$, p. 12). In terms of storage capacity, preliminary evaluations indicate that the capacity of the WCSB for CO2 storage could store emissions from all Alberta sources at 2000 levels for about 200 years (Griffiths et al., 2005).

This region is also in relatively close proximity to large point sources of $\mathrm{CO} 2$ such as coal fired power plants, refineries, pulp and paper operations and cement plants.

Unfortunately, one of the region's largest emitters of $\mathrm{CO}$, the oilsands developments in Northern Alberta, is not located near the WCSB. In this case, pipelines would need to be constructed to transport emissions to suitable geological storage sites in the southwest region of the province (Griffiths et al., 2005).

Another advantage Canada (particularly Western Canada) has in terms of CCS is industry related experience. Since 1989, regulations in Alberta have prohibited the incineration of sulphur gases released in the processing of sour gas. Many gas processing companies have since disposed of the waste "acid gas" by injecting it deep into the saline formations of the WCSB. This injection process is now at a commercial scale and is considered similar to potential CO2 injection (Griffiths et al., 2005). Acid gas has been disposed of through injection in depleted oil and gas reservoirs and deep saline aquifers for approximately 15 years. To date, there have been no reported safety incidents, leakage or other damaging environmental consequences (Griffiths et al., 2005).

Enhanced oil recovery (EOR) is another application for the injection and storage of $\mathrm{CO} 2$, particularly in the mature oil and gas reservoirs of the WCSB. The process involves the injection of $\mathrm{CO} 2$ at high pressure into near depleted oil reservoirs to recover the remaining reserves. The $\mathrm{CO} 2$ is then trapped in the depleted reserve after injection. As pointed out by Beauregard-
Tellier, EOR "is appealing when oil prices are high, as they have been in recent years. Such a price environment in turn increases the value of $\mathrm{CO} 2$ and can therefore considerably improve the economics of CCS" (2006, p. 2). Since 2000, Encana Corporation has applied the injection of $\mathrm{CO} 2$ for EOR in its Weyburn oil field in southeast Saskatchewan (BeauregardTellier, 2006). The CO2 is supplied via pipeline from a coal gasification plant about $330 \mathrm{~km}$ away in North Dakota. "At the conclusion of the project, some $19 \mathrm{Mt}$ of $\mathrm{CO} 2$ will have been sequestered in the reservoir" (IEA/OECD, 2004, p. 157). This pilot CCS project is "Canada's largest industrial greenhouse gas sequestration project to date" and "Field tests conducted as part of the ongoing IEA GHG Weyburn CO2 Monitoring and Storage Project, funded in part by the Government of Canada, have shown that the Weyburn oil field is suited to long-term geological storage of CO2" (Beauregard-Tellier, 2006, p. 2).

\subsection{International deployment of CCS}

The Weyburn project is one of three industrial-scale CCS projects currently in operation in the world. The other two CCS projects are offshore near Norway and in a gas field in Algeria (IPCC, 2005). While the Weyburn project was initiated primarily for EOR, in 1996 Norway's StatOil began to inject CO2 emissions into a deep saline aquifer in the North Sea as part of a climate change mitigation strategy precipitated by high taxes imposed by the Norwegian government on $\mathrm{CO} 2$ emissions (Griffiths et al., 2005). BP's In Salah project in Algeria involves the storage of $\mathrm{CO} 2$ in a gas field. Like the StatOil project, BP's In Salah CCS project "provides an opportunity to obtain baseline and monitoring data that is not associated with enhanced oil recovery" (Griffiths et al., 2005, p. 18).

A complete description of smaller scale and planned CCS projects is beyond the scope of this analysis. "There are one hundred ongoing and proposed geologic storage projects" (IEA/OECD, 2004, p. I5). However, the above description of current large scale CCS projects and analogous acid gas injection applications does provide an indication of the technological feasibility of CCS as a climate change mitigation strategy, particularly from a Canadian perspective.

\section{Barriers and Challenges to CCS Deployment}

There are a number of technological, economic, environmental, social and legal barriers that must be addressed before CCS can be successfully deployed in Canada and other parts of the world as an effective sustainable development mechanism. Since fossil fuels will likely continue to dominate energy production for the next few decades "most models also indicate that known technological options could achieve a broad range of atmospheric stabilization levels but that implementation 
would require socio-economic and institutional changes" (IPCC, 2005, p. 3). CCS is one of these technological options that will face such implementation challenges.

\section{I Economic Barriers}

The establishment of widely deployed CCS projects will require large scale infrastructure development, financing and construction. This scale of infrastructure is required to deploy CCS facilities to a degree required to contribute to mitigation of GHG emissions needed to stabilize the Earth's atmosphere by the end of the current century. Changes in the design of new large point emitters of $\mathrm{CO} 2$ will be required to accommodate carbon capture technology. Existing facilities like power plants and other industrial sites will require retrofits to integrate capture technology. In terms of transportation, new pipeline construction will be necessary to carry $\mathrm{CO} 2$ to suitable geological and other storage sites. However, CCS does face many of the challenges with the development of renewable energy sources. "One aspect of the cost competitiveness of CCS systems is that CCS technologies are compatible with most current energy infrastructures" (IPCC, 2005, p. 12).

All of the processes outlined above designed to capture and compress $\mathrm{CO} 2$ to render it transportable require additional energy. "It is generally agreed that the biggest cost element is capture but these costs should reduce with further research and development" (Parliamentary Office of Science and Technology, 2005, p. 3). The IPCC estimates that a power plant designed to capture $\mathrm{CO} 2$ will require $10-40 \%$ more energy to operate than a comparable plant without CCS capability (IPCC, 2005). This additional energy expenditure relates primarily to the capture and compression of CO2. However,"a power plant with CCS could reduce $\mathrm{CO} 2$ emissions to the atmosphere by approximately $80-90 \%$ compared to a plant without CCS" (IPCC, 2005, p. 4).

Industrial emitters of GHGs are unlikely to invest in mitigation technologies like CCS under the current cost structure with respect to $\mathrm{CO} 2$. Until the cost of emitting $\mathrm{CO} 2$ into the atmosphere is equivalent to that of deploying CCS technology, the cheaper alternative of atmospheric emissions will prevail. "The cost of CCS in Canada at present exceeds the federal government's commitment to cap costs of carbon credits at $\$ 15 /$ tonne in the Kyoto 2008-20I3 term" (Griffiths et al., 2005, p. viii). Until the cost of carbon reaches the cost of CCS deployment, industry will be reticent to invest in the technology.

\subsection{Legal barriers}

The most significant legal barrier to CCS is the determination of liability over the long term in the event of significant leakage of stored or transported $\mathrm{CO} 2$ into the atmosphere. Carbon storage is a long term proposition. The owners of CCS operations may not be in existence in the event of a severe $\mathrm{CO} 2$ leak at some point in the distant future. "Long-term liability issues associated with the leakage of $\mathrm{CO} 2$ to the atmosphere and local environment impacts are generally unresolved." (IPCC, 2005, p. I5). Regulations will need to address who is responsible for monitoring and reporting of carbon storage facilities over extended time frames. There are, however, legal frameworks that govern analogous activities. For example, in the United States there is "a large body of existing Federal law governing interstate pipeline activities, hazardous wastes and underground injection wells and their controls. These could be adapted to encompass CO2 storage activities" (IEA/OECD, 2004, p. 191).

Storage facilities, both underground and in the ocean, will cross international borders. International legal issues surrounding ownership, monitoring and environmental responsibility will need to be addressed as CCS applications grow.

A final legal barrier to CCS relates to how the technology will be integrated into current and future emission trading schemes (ETS). As pointed out in a recent Commission of the European Communities report "currently the positive $\mathrm{CO} 2$ reductions from CCS are not rewarded since CCS is not enabled as part of the EU-ETS nor the Clean Development Mechanism. If included, the $\mathrm{CO} 2$ reduction through CCS would be valued at the carbon price" $(2008$, p. 2). This issue of legal recognition of CCS as a carbon mitigation alternative is further complicated by the possibility of atmospheric leaks over long time frames. Creating a level playing field with other climate change mitigation strategies will require clear rules around "who owns any GHG emission credits and how are they discounted for leaks" (Griffiths et al., 2005, p. 57).

\subsection{Environmental barriers}

As with all human generated waste, $\mathrm{CO} 2$ disposal presents a number of known environmental hazards. If released in large quantities over short periods of time, $\mathrm{CO} 2$ can be fatal to humans and other animal life. "CO2 poses a risk if it replaces oxygen in air that is needed for breathing" (Griffiths et al., 2005, p. 50). Consequently, the storage of large accumulated quantities of $\mathrm{CO} 2$ presents some significant potential environmental challenges to the wide scale deployment of CCS. Underground storage of $\mathrm{CO} 2$ at quantities required to render $\mathrm{CCS}$ a viable emission mitigation technique is beyond the current technical experience of the energy industry. "So far, there is little experience with long-term $\mathrm{CO} 2$ storage and no proof that storage can be safely guaranteed over a period of centuries" (IEA/OECD, 2004, p. 42). 
The first most serious issue that needs to be addressed is the possibility of atmospheric leakage of $\mathrm{CO} 2$ after geological storage. The selection of appropriate geological storage sites is critical. The IPCC estimates that $\mathrm{CO} 2$ retention "in appropriately selected and managed geological reservoirs is very likely to exceed $99 \%$ over 100 years and is likely to exceed $99 \%$ over I,000 years" (2005, p. I4). In areas of active drilling such as the WCSB, there is concern that multiple drill holes have, over time, created weaknesses in the cap rock that could result in leaks of stored CO2. As pointed out by Griffiths et al. "mechanical flaws in wells and abandoned wells have been the most common cause of leaks in underground gas storage facilities" (2005, p. $5 \mathrm{I}$ ). Because $\mathrm{CO} 2$ is corrosive, there is concern that leakages could occur through concrete well heads in storage sites in abandoned oil wells or in EOR applications. Since large scale injection of $\mathrm{CO} 2$ is a relatively unproven activity, pressure caused by such a process poses the risk of triggering small seismic events (IPCC, 2005).

Risk of damaging CO2 leakage could also occur in the transportation phase of the storage process. This risk is considerably less than that of storage as industry experience with the safe transportation of industrial substances through pipelines is quite extensive. However, given the relatively greater corrosive properties of $\mathrm{CO} 2$, the risk of leakage is somewhat greater than with other substances (Griffiths et al., 2005). Also, any increase in pipeline construction will disrupt natural habitat and animal migration patterns.

\subsection{Other barriers}

Public perception will be a significant barrier to wide scale deployment of CCS. Legitimate concerns over the long term safety of CCS will need to be addressed. Additional research and results from the existing CCS pilot projects as outlined above will need to be communicated to the public. Public support will be crucial if adequate government funding is to be generated for early stage development and research into CCS deployment. "Industry and government bodies are enthusiastic about CCS as a way of reducing GHG emissions, but they recognize that if CCS is to succeed, it must be acceptable to the public" (Griffiths et al., 2005, p. 63).

Many environmental groups have raised concerns about the science of CCS and its relative merits as an emissions reduction strategy. "Geosequestration is an end of pipe response to climate change that shifts the responsibility of managing our waste to our children and our children's children" (CANA, 2004, p. I). CANA has also pointed out that the resources deployed to develop and implement CCS will divert resources away from the development of renewable energy and other energy efficiency measures (2004). CANA has also expressed concerns that the timeline for implementation of CCS is far too long relative to the more immediate need to significantly reduce GHG levels. While some environmental organizations recognize the need to develop CCS as part of an overall emissions reduction strategy, others "want to keep their distance, calling carbon capture and storage an 'addict's response' to climate change" (Socolow \& Greenblatt, 2004, p. 17).

\section{Canadian Advantages to CCS Deployment}

While there are significant hurdles to be overcome in making widespread deployment of CCS a reality, Canada is in a unique position to be a world leader in the implementation of CCS as a GHG reduction mechanism. Since CCS technology is based on many existing and proven technologies in the energy sector (particularly with oil and gas drilling, EOR, underground storage of natural gas and pipeline construction and operation), Canadian industry is well positioned to undertake CCS deployment. "First and foremost, Canada is endowed with an abundance of fossil fuels (including an unparalleled oil sands resource), around which a very strong set of industry sectors already exist" (Natural Resources Canada, 2006, p. vii).

As demonstrated through the Weyburn CCS pilot project, the WCSB is one of the world's best geological formations for deep storage of CO2. "Canada's biggest advantage lies just underground. Stable sedimentary rock formations like the WCSB are ideal for CO2 storage" (eCCSTF, 2008, p. vi). In addition, the WCSB is located near large point sources of CO2 emissions. In particular, this location advantage includes reasonable proximity to the Northern Alberta oilsands, considered to be one of the largest industrial projects in the world and, consequently, a significant contributor to growing GHG emissions. "The Tar Sands are ground zero for global warming for two reasons. First, it is the fastest growing source of greenhouse gas emissions in Canada. Tar Sands emissions -not counting burning the oil later- are estimated at about 40 million tonnes for 2007 , but if left unchecked this could explode to I 42 million by 2020." (Hatch \& Price, 2008, p. I6)'. Capture and storage of oil sands related GHGs represents a significant advantage to the Canadian development of CCS.

Canada's industry fossil fuel industry experience and geological storage endowment also present significant international business opportunities with respect to CCS technology. "Canadian researchers and energy industries are already recognized internationally in certain areas of CCS, and if Canada maintains its competitiveness, it could reap large economic advantages" (Natural Resources Canada, 2006, p. vii). International opportunities to deploy Canadian CCS expertise are significant. Advances in climate change mitigation strategies like CCS will have significant international implications and opportunities "es- 
pecially on the battlegrounds where the war against global warming will be won or lost, such as China, where a $600 \mathrm{MW}$ coalfired power plant is built every two weeks" (Heaps, 2007, p. 48).

\section{Speculating the Future}

The predicted global long-term demand for oil will likely keep prices high enough to encourage many Canadian oil producers and refinery operators to use CCS technology, but only if Government legislation on GHG reduction is enforced. Producers and refiners will have to be driven simultaneously by the profit margin of their product, and by the legislation that requires their operation become environmentally sustainable; and as a very positive side benefit, the producers can legitimately claim (and be seen) to being doing the "right thing" for the environment.

Besides the Western Canada Sedimentary Basin (WCSB), Eastern Canadian fossil-fired power producers may well consider the vast resource of deep $\mathrm{CO} 2$ capture under the Canadian Shield (a dense, impermeable cap rock that covers extensive areas of eastern and north-eastern Canada).This potentially would be an attractive disposal zone to Eastern power producers ${ }^{2}$. So the action need not be limited to western Canada.

CCS is likely to become more efficient and less costly to implement as the technology advances. The important thing is giving it a push-start today, which will probably come from the combination of high oil prices, Government Legislation and pressure on both parties from environmental groups to take action to protect the environment. From strictly the economic motive, the continued high global demand for energy will leave producers in a rather weak position if they continue to maintain the status quo of "not doing anything", since they are increasingly seen to be able to afford to implement some of these technologies, and particularly since they all claim to want to protect the environment.

CCS is directly applicable to coal-fired power plants, and may become a key technology for keeping (abundant) coal as important fossil fuel. It is possible that Canadian leadership in CCS technology development may itself become a profitable enterprise through licensing agreements with overseas producers and play a significant role in bridging the gap between economic progress and environmental stewardship in emerging economics such as India and China.
Hopefully, at least one oil sands producer will implement a form of this technology within the next phase of development by collecting, compressing and injecting $\mathrm{CO} 2$ emissions into the tailings ponds. This will enhance the settling rate of fine clay particles in the tailings ponds, enable greater water recycle and achieve better recovery of bitumen from the oil sands (i.e. the triple benefit of lower GHG emissions, lower water withdrawals from the Athabasca River and greater bitumen recovery).

\section{Conclusion}

CCS is not a panacea in the increasingly urgent battle over the effects of rising levels of CO2 in the Earth's atmosphere. There are five strategies required to keep the trajectory of $\mathrm{CO} 2$ emissions relatively flat over the next 50 years - energy conservation, renewable energy, enhanced natural sinks, nuclear energy, and fossil carbon management (Socolow \& Greenblatt, 2004). CCS fits in the last strategy. Socolow \& Greenblatt estimate there are seven "wedges" required to stabilize CO2 emissions at current levels over the next 50 years (2004). As world dependence on fossil fuel consumption shows no signs of dwindling over the next few decades, CCS deployment is an important contributor to one of these stabilization wedges. Dedication to only one emissions reduction strategy or "wedge" like CCS will not solve the problem of GHG accumulation. "Advocates of any one wedge should take a cleareyed look at the difficulties inherent in cutting one billion tons of carbon emissions per year using that strategy" (Socolow \& Greenblatt, 2004, p. 18).

With the above caution in mind combined with the technological, economic and other barriers outlined above, CCS does represent a promising technology to help deal with $\mathrm{CO} 2$ emissions, particularly from a Canadian perspective. Experiences with smaller scale CCS pilot projects around the world are showing positive results. The next steps in terms of developing appropriate controls and international agreements around large scale CCS application will be crucial for this technology to be implemented in a time frame that meets global emission reduction requirements. Finally, CCS has the potential to act as a conduit to a new energy world that is less reliant on fossil fuels. "Ultimately, we consider such technologies a bridge to a more carbon-constrained future, a medium-term solution" (Holliday et al., 2002, p. 228).

I The second reason mentioned by Hatch \& Price (2008, p. I6) relates to the political dynamics that result from the Federal politicians reluctance to put real caps on GHG emissions from the tar Sands.

2 This geological formation was, and perhaps still is being considered as deep disposal for spent radioactive fuel for Nuclear Power Plants in Eastern Canada. 


\section{References}

BEAUREGARD-TELLIER, F. (2006). The Economics of Carbon Capture and Storage. Ottawa: Library of Parliament. Retrieved February 13, 2008 from: http://www.parl.gc.ca/information/library/ PRBpubs/prb05 I03-e.htm

Climate Action Network Australia (CANA). (2004). Geosequestration and Climate Change: Media Briefing. Author. Retrieved February 18, 2008 from http://www.cana.net.au/ index.php?site_var $=336$

Commission of the European Communities. (2008). Proposal for a Directive of the European Parliament and the Council on the geological storage of carbon dioxide. Brussels: Author. Retrieved February 20, 2008 from https://www.wbcsd.org/plugins/DocSearch/details.asp?txtDocTitle=carbon\%20 capture\&txt DocText $=\mathrm{carb}$ on $\% 20 \mathrm{capture \& DocTypeld=-}$ I \&Objectld=MjgzMDY\&URLBack=result\%2Easp\%3FtxtDocTit| e\%3Dcarbon+capture\%26txtDocText\%3Dcarbon+capture\%26DocTypeld\%3D\%2D I\%26SortOrder\%3D\%26CurPage $\% 3 \mathrm{DI}$

GRIFFITHS, M., Cobb, P. \& Marr-Laing,T. (2005). Carbon Capture and Storage: An arrow in the quiver or a silver bullet to combat climate change? A Canadian Primer. The Pembina Institute. Retrieved February 13, 2008 from http://www.pembina.org/ pub/584

HATCH, C. \& Price M. (2008). Canada's Toxic Tar Sands: The Most Destructive Project on Earth. Toronto: Environmental Defence. Retrieved February 29, 2008 from: http://www.environmentaldefence.ca/reports/tarsands.htm

HEAPS, T. (2007). The War on Global Warming. Corporate Knights, Urbanization Issue.

HOLLIDAY, C., Schmidheiny, S., \& Watts, P. (2002). Walking the Talk:The Business Case for Sustainable Development. Aizlewood's Mill, NJ: Greenleaf Publishing Limited.

International Energy Agency \& Organization for Economic Cooperation and Development (IEA/OECD). (2004). Prospects for CO2 Capture and Storage. Paris: Author. Retrieved February 22, 2008 from http://www.cslforum.org/publications.htm

Natural Resources Canada. (2006). Canada's CO2 Capture \& Storage Technology Roadmap. Author. Retrieved February 27, 2008 from http://www.nrcan.gc.ca/es/etb/cetc/combustion/ co2trm/htmldocs/ccstrm_doc_e.html
Parliamentary Office of Science and Technology. (2005). Carbon Capture and Storage (CCS). London: Author. Retrieved February 13, 2008 from www.parliament.uk/documents/upload/POSTpn238.pdf

SOCOLOW, R. \& Greenblatt, J. (2004, December). Solving the Climate Problem: Technologies Available to Curb CO2 Emissions. Environment, 46(10), 8-19. Retrieved February 27, 2008 from http://www.ico2n.com/technical.php

The ecoENERGY Carbon Capture and Storage Task Force. (2008) Canada's Fossil Energy Future: The Way Forward on Carbon Capture and Storage. Author. Retrieved February 10, 2008 from http://www.nrcan-rncan.gc.ca/com/resoress/publications/fosfos/fosfos-eng.pdf

Williams, T. (2006). Carbon Capture and Storage: Technology, Capacity and Limitations. Ottawa: Library of Parliament. Retrieved February 13, 2008 from: www.parl.gc.ca/information/library/PRBpubs/prb0589-e.pdf

Working Group III of the Intergovernmental Panel on Climate Change. (2005). IPCC Special Report on Carbon Dioxide Capture and Storage. New York: Cambridge University Press. Retrieved January 30, 2008 from http://www.ipcc.ch/ipccreports/srccs.htm 